\title{
Innovative Approach for Classification of Traditional System of Medicine
}

\author{
Jadhav Priyanka $\mathbf{M}^{1 *}$ and Kshirsagar Nilima $\mathbf{A}^{2}$
}

${ }^{1}$ Department of Pathology, Immunology and Laboratory Medicine, College of Medicine, University of Florida, USA

${ }^{2}$ Department of Infectious Diseases, Maharashtra University of Health Sciences, Mumbai, India

\begin{abstract}
Traditional medicines form the integral part of the health care system for the developing countries serving around $80 \%$ of the world population and are widely used as over the counter medication. There is urgent need to classify the traditional medicines to facilitate utilization data, safety and efficacy data, quality control measures and provide new avenues for further drug research. Medical texts of Ayurveda have classified the herbs as per their therapeutic indication, but these texts are in Sanskrit or in regional language. This makes it difficult for researchers all over world to access, understand and interpret information. We here propose to adapt the traditional classification to WHO-HATC (World Health Organization: Herbal Anatomical-Therapeutic-Chemical Classification) method to facilitate the classification in Scientific names in a standardized uniform way and further understanding of the utility of herbs in different therapeutic areas. Thus this innovative approach of classification can serve as one stop source of all recent updated information on the herbal drug research for the academia and industry both. This classification can be used in a pragmatic, transparent, hierarchical way in a computerized system to capture and use information of various degrees of precision.
\end{abstract}

Keywords: Herb classification; Traditional system of medicine (TSM); WHO-HATC; Ayurveda

\section{Introduction and Background Information}

Traditional medicines form the integral part of the health care system for the developing countries. As per WHO statistics, in some Asian and African countries, $80 \%$ of the population depends on traditional medicine for primary health care. In many developed countries, $70-80 \%$ of the population has used some form of alternative or complementary medicine (e.g., acupuncture) [1]. The availability of herbal medicines to the general public is very wide compared to conventional and over the counter medicinal products. They are typically used for self medication or prescribed by the traditional healer, and in management of personal health including management or prevention of the onset of chronic disease, boosting overall general well-being and cognitive function, and increasing longevity [2]. Since herbal products are not included in the regular pharmaceuticals supply chains, the extent to which herbals are used in populations is largely unknown, and utilization data is difficult to assemble. Further, herbal medicinal products do not go through the same rigorous scientific testing for efficacy and safety as allopathic medicines. Drug utilization studies aim to evaluate factors related to the prescribing, dispensing, administering and taking of medication, and its associated events (either beneficial or adverse) [3]. The modern medicines are classified as per ATC/DDD (Anatomical-Therapeutic-Chemical/ Daily Defined Dose) by WHO. The purpose of the ATC/DDD system is to serve as a tool for drug utilization research in order to improve quality of drug use. One component of this is the presentation and comparison of drug consumption statistics at international and other levels [4]. Thus to enable herbal drug utilization research and safety monitoring, the existing systems to capture, storage and analysis of data, needs to be adapted to accommodate relevant information on herbal products.

Thus very clearly, there is a need for effective risk management strategies to cover herbal products. The safety issues associated with the use of herbal products, and their public health impact, have to be evaluated and communicated [5].

Indian herbal market is registering an extremely significant growth internationally, and is likely to reach Rs. 14, 500 crore (USD 3100 million) by 2012 and exports to Rs. 9,000 crore (USD 1800 million) with a CAGR (Compound Annual Growth Rate) of 20\% and 25\% respectively, according to findings of the Associated Chambers of Commerce and Industry of India. The stringent quality norms as imposed by the directives of EU through the Traditional Herbal Medicinal Products Directive (THMPD) and Food Supplement
Directive (FSD) will encourage the high quality products and subsequently lead to the rejection of unorganized sectors sub-standard products [6].

Reverse pharmacology approach can enable scientific analysis of the de novo actions of natural products in development of safe, effective and acceptable therapeutic agents [7]. Classification of herbal medicines would facilitate scientific and methodological approach to discover, characterize and standardize these multicomponent botanical therapeutics [8].

It is evident from above reasons that there is urgent need to classify the traditional medicines to facilitate utilization data, safety and efficacy data, quality control measures and provide new avenues for further drug research [9-13]. We have compiled the methods of traditional classification and the modern methods and made an attempt to propose an innovative approach to classify traditional system of medicine (TSM).

\section{Indian Methods of Classification of Herbal Medicine}

Charak Samhita ( $2^{\text {nd }}$ Century BC) in its Sutrasthana in chapter 4: Shadvirechanshatashritiya Adyaya explains 50 groups of medicinal plants classified as per their therapeutic indication. Table 1 exemplifies the classes mentioned by Acharya Charak and the English translations of the names of those classes. Please note the English versions are for the general understanding and not for replacement or representation of their functions. Table 2 represents the same classification by Charak with further modification and representation. The functions and properties of Charak is retained but the representation is made in a classifiable method. Each group has 10 plants in it and is called as "Mahakashaya". Example of some of the mahakashyas are Arshoghana Mahakashaya (Herbs used in piles) containing Kutaja (Holarrhena

*Corresponding author: Priyanka M. Jadhav, Department of Pathology, Immunology and Laboratory Medicine, College of Medicine, University of Florida, USA, Tel: (001)352-231-2230; E-mail: priyanka.ing@gmail.com

Received August 18, 2015; Accepted Septemebr 23, 2015; Published Septemebr 29, 2015

Citation: Priyanka MJ, Nilima AK (2015) Innovative Approach for Classification of Traditional System of Medicine. Nat Prod Chem Res 3: 191. doi:10.4172/2329-6836.1000191

Copyright: (c) 2015 Priyanka MJ, et al. This is an open-access article distributed under the terms of the Creative Commons Attribution License, which permits unrestricted use, distribution, and reproduction in any medium, provided the original author and source are credited. 
Citation: Priyanka MJ, Nilima AK (2015) Innovative Approach for Classification of Traditional System of Medicine. Nat Prod Chem Res 3: 191. doi:10.4172/2329-6836.1000191

antidysentrica Wall.), Bilva (Aegle marmelous Corr.) and Kandu ghana Mahakashaya (Herbs used in purities) consisting Aaragvadha (Cassia fistula Linn.), Karanja (Pongamia glabra Vent.) [7]. The classification of medicinal plants in Ayurveda is not binomial as the modern classification. The plants are named as per the habitat, shape, size, therapeutic utility, etc. One plant can have up to 50 names and one name can be given to various plants. This mention in "Aushad chatuska" of mahakashayas is one of the many kinds of classification mentioned in text. Acharya Charka also mentions many other types of classification including, as per the Rasa (taste) (chapter 1, Sutrasthana), panchmahabhuta (5 elements viz-a-viz earth, water, fire, air, vacuum) (chapter 1, Sutrasthana), according to the plant part used (mulini, falini, etc) (chapter 1, Sutrasthana), as per the use for panch karma treatment (chapter 8, Vimanasthana), etc [14].

Sushruta Samhita ( $2^{\text {nd }}$ Century AD) classifies the medicinal plants in group of drugs as per their therapeutic use. The groups are named as per the herbs included in them and not as per their therapeutic indication. These groups represent the collection of herbs with similar indications e.g., Aaraghvadadi gana constitutes of Cassia fistula, Azadiracta indica, Tinospora cordifolia, etc for wound cleansing [15]. Vagbhatt ( $6^{\text {th }}$ Century AD) has classified the herbs as per their therapeutic application and indication. This makes it difficult to understand and interpret the classification as varied names of herbs are been used. Yet this classification is widely used by traditional practitioners successfully, indicating the evidence of their practical applicability. Table 3 represents other method of classification as per Acharya Vagbhat [16].

In Ras-ratna Sammuchaya (12 $2^{\text {th }}$ Century AD) the metals and minerals (Rasa and Uprasa) and their formulations are described vividly.
Sodhal and Sharangdhar samhitas (12-13 ${ }^{\text {th }}$ Century) Bhavprakash $\left(16^{\text {th }}\right.$ Century AD) added new medicinal plants imported by Moghuls e.g., Papaver somniferum and Chopchini [17]. Yogratnakar and Shaligram nighantu (17 and $18^{\text {th }}$ Century) added new medicinal plants imported by British e.g., Tobacco [18].

Some recent authors have attempted to classify the medicinal plants as per their therapeutic utility. Priyavrat Sharma in his book "Drava-guna vigyan" classifies the medicinal plants as per their modern pharmacological use. He has classified the medicinal plants broadly into 14 classes e.g., Chedan/Sleshmahar (Expectorant): Adhatoda vasica, Glycyrrhiza glabra Linn [19].

\section{The WHO Initiative}

The Uppsala Monitoring Centre (UMC) collects and analyses reports of suspected adverse drug reactions from worldwide members of the International Drug Monitoring programme and issues signals of international drug safety concerns arising from the data. Individual case safety reports received by the UMC are stored in the WHO Adverse Drug Reaction database. Till 2004, it contained more than three million reports from 73 countries. More than 30,000 of these reports mentioned medicinal products containing herbal ingredients and the number was increasing rapidly.

Following this, the Uppsala Monitoring Centre, WHO Collaborating Centre for International Drug Monitoring released "Guidelines for Herbal ATC classification and Herbal ATC Index" in 2004. The Herbal ATC (HATC) provides an administrative tool for putting groups of drugs into systems according to therapeutic categories and was thought to be useful for a number of medical, scientific and

\begin{tabular}{|c|c|c|c|c|c|}
\hline S No & Sanskrit name & English name (Translated) & S No & Sanskrit name & English name (Translated) \\
\hline $\mathbf{1}$ & Jeevaniya & Drugs increasing Vitality/ Restorative drugs & $\mathbf{1 1}$ & Truptighna & Appetite enhancers \\
\hline $\mathbf{2}$ & Bruhaniya & Mass promoting drugs & $\mathbf{1 2}$ & Arshoghna & Anti heamorrhoidals \\
\hline $\mathbf{3}$ & Lekhaniya & Mass reducing drugs & $\mathbf{1 3}$ & Kusthaghna & Drugs for skin aliments \\
\hline $\mathbf{4}$ & Bhedaniya & Purgatives $^{*}$ & $\mathbf{1 4}$ & Kandughna & Anti-pruritic \\
\hline $\mathbf{5}$ & Sandhaniya & Union promoters/ healing promoters & $\mathbf{1 5}$ & Krumighna & Anti-helminthic \\
\hline $\mathbf{6}$ & Dipaniya & Stomachics and Digestives & $\mathbf{1 6}$ & Vishaghna & Antidotes/ Drugs for various poison \\
\hline $\mathbf{7}$ & Balya & Tonics & $\mathbf{1 7}$ & Stanyajanan & Galactogogues \\
\hline $\mathbf{8}$ & Varnya & Complexion promoters/ complexion lightening drugs & $\mathbf{1 8}$ & Stanyashodhan & Galacto purifiers/ drugs for ailments related to breast milk \\
\hline $\mathbf{9}$ & Kanthya & Voice promoters & $\mathbf{1 9}$ & Shukrajanan & Spermo-poietic \\
\hline $\mathbf{1 0}$ & Hridya & Cardiac tonics & $\mathbf{2 0}$ & Shukrashodhan & Spermo-purifiers/ drugs for ailments related to \\
& spermopoesis/semen & & \\
\hline
\end{tabular}

Note: "The English translations are not done with aim of term replacement and are translations of the Sanskrit terms. The terms are translated for mere understanding of the Ayurvedic drug groups and are not representing their functions. The actual translation of Ayurvedic terms is out of scope of this paper. These terms are mere English translations

Table 1: Representative table giving details of the groups of traditional drugs as per Charak Samhita.

\begin{tabular}{|c|c|c|c|c|c|}
\hline \multicolumn{2}{|c|}{ A Alimentary Tract and Metabolism } & \multirow[b]{2}{*}{ A01 drugs acting on mass } & \multirow[b]{3}{*}{ A01A-Bruhaniya (Mass promoting drugs) } & & \multirow[b]{4}{*}{ arundiaceum } \\
\hline & & & & & \\
\hline & & & & \multirow[b]{2}{*}{ Liliaceae } & \\
\hline & & & Kshirini (Swetamusli) & & \\
\hline & & & A01B- Lekhaniya (Mass reducing drugs) & \multirow[b]{2}{*}{ Zingiberaceae } & \\
\hline & & & Haridra & & Curcuma longa Linn. \\
\hline \multicolumn{2}{|c|}{ B Blood and blood forming organs } & B01 Anti-hemorrhagics & B01A Arshoghna Anti heamorrhoidals & & \\
\hline & & & Kutaja & Apocynaceae & $\begin{array}{l}\text { Holarrhena antidysentrica } \\
\text { Wall. Ex A. DC. }\end{array}$ \\
\hline \multirow[t]{2}{*}{ B02 } & $\begin{array}{l}\text { B02A } \\
\text { Haemost }\end{array}$ & $\begin{array}{l}\text { Shonit sthapana } \\
\text { tics }\end{array}$ & & & \\
\hline & & & Lodhra & Symplocaceae & Symplocos racemosa Roxb. \\
\hline
\end{tabular}

Table 2: Representative table giving details of the groups of traditional drugs as per their therapeutic indication given in Charak Samhita. 
Citation: Priyanka MJ, Nilima AK (2015) Innovative Approach for Classification of Traditional System of Medicine. Nat Prod Chem Res 3: 191. doi:10.4172/2329-6836.1000191

Page 3 of 5

\begin{tabular}{|l|l|l|}
\hline S No & Herbs/groups & Indication \\
\hline 1 & $\begin{array}{l}\text { Patoladi gana constituting of } \\
\text { Trichosanthes dioica Roxb., Picrorhiza kurroa Royle.ex Benth., Santalum album L., Tinospora cordifolia (Thunb.) } \\
\text { Miers., Cissampelos pareira Linn., etc. }\end{array}$ & $\begin{array}{l}\text { Skin disorder, fever, toxicity, nausea, jaundice, } \\
\text { etc. }\end{array}$ \\
\hline 2 & $\begin{array}{l}\text { Surasadi gana constituting of } \\
\text { Ocimum sanctum Linn., Clerodendron serratum (L.) SPRENG., Vitex negundo Linn., Embelia ribes Burm.f., etc. }\end{array}$ & Worm infestation, rhinitis, asthma, cough, etc. \\
\hline
\end{tabular}

Table 3: Representative table giving details of the groups of traditional drugs as per Vagbhat Samhita.

administrative purposes and particularly for the monitoring of adverse effects of herbal drugs.

To be able to better identify safety problems related to herbal products, the Herbal ATC has now been fully implemented within the WHO Drug Dictionary (WHO-DD). For example, by investigating groups of herbal drugs with similar therapeutic, pharmacological and chemical properties it is possible to find out if the adverse drug reaction is caused by a specific herbal product or if it is a group effect. All herbal substances which are ingredients of recorded medicinal products in the WHO-DD have been assigned HATC codes according to these guidelines. In addition, all new medicinal products entered into the system are assigned HATC codes on the product level. The final step, undertaken by the UMC, was to assign HATC codes to all previously entered products. As a result of this work, all reports of safety problems involving herbal products can easily be retrieved and grouped using the pre assigned HATC codes. Since there is an extensive use of synonyms to herbal substance names, both other botanical names in Scientific and local (common) names, the UMC has produced a checklist linking all synonyms to the accepted botanical names entered in the WHO-DD. In 1998, De Smet proposed a system for ATC classification of herbal remedies which is fully compatible with the regular system. With a few modifications this system was adopted and described in "Guidelines for Herbal ATC classification": the Uppsala Monitoring Centre. The Herbal ATC system (HATC) presented in these guidelines provides a unique scientific framework for a harmonized, global nomenclature and therapeutic classification of herbal substances and combinations of them [5].

\section{WHO HATC System}

\section{General guidelines for ATC classification}

Active substances of the drugs are classified in groups at 5 different levels according to the organ or system on which they act and their therapeutic, pharmacological and chemical properties. Drugs are divided into 14 main groups which constitutes the $1^{\text {st }}$ level of anatomical groups designed by the letters $\mathrm{A}-\mathrm{V}$. The $2^{\text {nd }}$ level is of Pharmacological/therapeutic subgroup. The $3^{\text {rd }}$ and $4^{\text {th }}$ levels constitute of Chemical/ pharmacological/ therapeutic. While the $5^{\text {th }}$ level is of Chemical substance or individual crude drug for herbal preparations (Table 4). The complete classification, in the Herbal ATC system, of preparations of Aloe ferox Mill, dry leaf juice, which is used as a laxative, illustrates the application of this structure (Table 4).

\section{For classification of combined preparations}

Preparations containing two or more crude drugs are regarded as combined preparations. Traditionally many drugs are given as combinations. Single herb use is highly limited. These combinations are classified according to two main principles:

All combined preparations containing two or more crude drugs belonging to the same therapeutic $4^{\text {th }}$ level, i.e., having similar Chemical/ pharmacological/ therapeutic properties, are classified using $5^{\text {th }}$ level codes starting at 9001 (followed by 9002, 9003, etc.). Combined preparations containing two or more crude drugs not belonging to the same therapeutic group (i.e., $4^{\text {th }}$ level) are classified by using $5^{\text {th }}$ level codes starting at 9501 (followed by 9502,9503 ). Thus by the initials of $5^{\text {th }}$ level, whether the multiple ingredients of the combination have similar Chemical/ pharmacological/ therapeutic properties can be identified.

\section{Other methods of classifications in Monographs and Pharmacopoeias}

Indian Pharmacopoeia has monographs of 55 herbs in herbal section. The herbs and herbal products are classified as per the Sanskrit names [20].

6 volumes of Ayurvedic Pharmacopoeia of India are published by Government of India. The total number of monographs of single drugs of plant origin in these 6 volumes is around 418. They are classified as per their common names (Sanskrit) [21].

United States Pharmacopoeia has monograph of 30 herbal extracts mentioned with details of their local use and side effects. The herbs are classified as per their local American names [22].

Physician Desk Reference for Herbal Medicine has both local and scientific names of around 600 herbal monographs. It also has alphabetical and indication index which makes searching of the herbs much easier [23].

Indian Herbal Pharmacopoeia revised edition was brought out by Indian Drug Manufacturers' Association (IDMA) in 2002. It follows the initial two volumes comprising of 40 monographs on Indian medicinal plants. The new edition covers 52 monographs on Indian medicinal plants, of immense medicinal value, largely used in the country and the world over. Authentic data based on scientific studies and investigation carried out in the institutions and research laboratories are published in this book. The publications available on individual plants are also referred under each monograph [24].

WHO monograph has classified the medicinal plants as per the scientific names and as per the alphabetical order. Volume 1 contains 28 monographs published in 1999. Volume 2, published in 2003 includes 30 monographs. Volume 3 in this series was published in 2007 and includes 31 monographs. Volume 4 , which is currently under editing, will include 28 monographs [25]. ESCOP (European Scientific Cooperative for Phytotherapy) has produced 80 monographs on herbal drugs. As part of ESCOP's programme to expand and update the range of monographs, the Supplement 2009 added 27 new monographs to the eighty published in 2003 , as well as 8 monographs revised to include recent data from herbal research. Extensive references to scientific literature form an important part of each monograph and over 1800 new citations appear in the book [26]. Although many other monographs and pharmacopoeias are published, they are classified as per the local names, which make it difficult to search such databases. The therapeutic indication is as per the regional use. We still lack a system which classifies the herbal monographs and details as per the scientific names and are inclusive of all the indications used over the world. A comprehensive, standardized and inclusive classification is the need of hour. 
Citation: Priyanka MJ, Nilima AK (2015) Innovative Approach for Classification of Traditional System of Medicine. Nat Prod Chem Res 3: 191. doi:10.4172/2329-6836.1000191

Ayurveda, as mentioned earlier, classifies the herbs systematically and as per their therapeutic indication. This format of classification by Ayurveda adapted with HATC classification can become a base for the standardized way of classification of herbs all over the world. For example: Based on WHO-HATC classification, the indications can be classified as per the systems of modern medicine to enable understanding of the indication. Like Balya gana i.e., the drugs used as tonics and Chardi-nigrahan gana i.e., Anti-emetics, can be classified in Alimentary tract and Metabolism Level. Although it must be considered that there are many other factors involved in decision of these classes (Table 4). Level 1, 2 and 3 classification can be done as per the traditional knowledge and level 4 and 5 can be updated regularly on basis of further studies done for isolation and characterization of herbal compounds. Other systems of medicine can also be pooled in this classification in the same way.

The therapeutic indications mentioned in Ayurveda have time and again stood the test of time. This innovative and modified classification system can enable scientists all over the world to pick up leads from this updated knowledge of tradition medicines. This would also facilitate the utilization studies and enable understanding of the aspects of pharmacovigilance of traditional medicine.

\section{Innovative approach for the classification}

The classification mentioned in Ayurveda i.e., Indian traditional medicine can be used based on the therapeutic indication and can be adapted to WHO-HATC format (e.g., Table 4 and Table 5). One difficulty with herbal drugs is that the indications for their use are more numerous than the indications for regular drugs. The same herbal drug can also find very different uses in different countries. Also one indication can have multiple drugs as therapy. It is thus necessary to use more than one HATC code for the same herbal drug. In cases where a higher number of indications are found in the literature, choice can be made between them by consulting the experts and considering frequent or significant use. This choice can be subjective to certain degree and probably reflects mainly opinions in the Western World, when we discuss the classification by WHO or others. This would facilitate the classification in botanical names in a standardized uniform way and further understanding of the utility of herbs in different therapeutic areas as per the traditional use. With further studies on these herbs and combinations, along with comprehensive compilation of studies done, level 4 and 5 of the database can be updated. Isolated compounds or chemical entities are not indicative of the efficacy in traditional context. Yet the compilation of discovered compounds in a systematic manner will help further researchers to get access to a reliable database and work on the enriched knowledge of ancestors, to progress it further in fundamental and basic understanding. Considering this mahakashya classification and WHO-HATC template to begin with we can arrange the vast spread information of traditional medicine present over numerous books and traditional practitioners, and of numerous herbs and their combinations.

Thus the database can serve as one stop source of all recent updated information on the herbal drug research for the academia and industry both. The traditional method of classification can prove beneficial for classification of many herbal medicines by internationally approved scientific binomial classification, and common therapeutic use as mentioned in classical texts. The new data obtained from these medicines can be updated regularly and would provide a way to disseminate this knowledge amongst all traditional practitioners and researchers around the globe. The medicinal products can be linked with WHO Drug Dictionary, WHO herbal dictionary and drug safety surveillance of herbal/traditional medicines can be done efficiently. The classification mentioned in classical texts can thus be used for various utilization studies and for exploring their therapeutic utility by various methods in drug discovery and development. This classification can be

Level 0: Herbal remedy designed by the letter $\mathrm{H}$

Level 1: 14 anatomical groups designed by the letters. A-V (the same in both systems)

Level 2: Comprises different therapeutic main groups, designed by numbers in both systems.

Level 3: Represents a therapeutic/pharmacological subdivision which is designated by letters. Where the regular system does not provide appropriate $3^{\text {rd }}$ levels, new levels are created. To avoid conflicts with the regular system, the letters $\mathrm{W}, \mathrm{Y}$ and $\mathrm{Z}$ are used.

Level 4: Comprises a therapeutic/ pharmacological/chemical subgroup. In this level the pharmacological properties and the chemical nature of the pharmacologically active compound(s) present in the crude drug are taken into account.

Level 5: (designated by numbers) is the individual crude drug. The numbers start at 5001 (followed by 5002 , 5003, etc) except for combination drugs, which start at 9001(followed by 9002,9003 , etc).

Illustration of Aloe ferox Mill. Classification as per WHO: HATC

H Herbal remedy (Level 0 )

A Alimentary tract and metabolism (1st level, anatomical main group)

06 Herbal laxatives (2nd level group, therapeutic main group)

A Herbal laxatives (3rd level group, therapeutic/pharmacological subgroup)

B Herbal contact laxatives (4th level group, therapeutic pharmacological/chemical subgroup)

5001 Aloe ferox Mill.,dry leaf juice (5th level group, individual crude drug)

Table 4: The structure of the herbal system as per WHO: HATC.

\begin{tabular}{|c|c|c|c|c|c|c|c|}
\hline & & Level & & Group name & & & \\
\hline S No & Level 1 & & Level 2 & & Level 3 & Sanskrit & English (Translated) \\
\hline \multirow[t]{2}{*}{1} & A & Alimentary Tract and Metabolism & A01 & Drugs acting on mass & & & \\
\hline & & & & & A01A & Bruhaniya & Mass promoting drugs \\
\hline & & & A01B & Lekhaniya & Mass reducing drugs \\
\hline & & & A02 & Laxatives & & & \\
\hline & & & & & A02A & Bhedaniya & Purgatives \\
\hline \multirow[t]{2}{*}{2} & \multirow[t]{2}{*}{ B } & \multirow{2}{*}{ Blood and blood forming organs } & \multirow[t]{2}{*}{ B01 } & Anti-hemorrhagics & & & \\
\hline & & & & & B01A & Arshoghna & Anti heamorrhoidals \\
\hline & & & B02 & Haemostatics & & & \\
\hline & & & & & B02A & Shonit sthapana & Haemostatics \\
\hline
\end{tabular}

Table 5: Example of traditional classification adopted in HATC system. 
Citation: Priyanka MJ, Nilima AK (2015) Innovative Approach for Classification of Traditional System of Medicine. Nat Prod Chem Res 3: 191. doi:10.4172/2329-6836.1000191

used in a pragmatic, transparent, hierarchical way in a computerized system to capture and use information of various degrees of precision.

\section{References}

1. World Health Organization (2008) Traditional Medicine. WHO Fact sheet No 134.

2. Leung JM, Dzankic S, Manku K, Yuan S (2001) The Prevalence and Predictors of the Use of Alternative Medicine in Presurgical Patients in Five California Hospitals. Anesthesia \& Analgesia 93: 1062-1068.

3. Helena Gama (2008) Drug Utilization Studies. Arquivos De Medicina 22: 69-74.

4. Guidelines for ATC classification and DDD assignment (2010) International language for drug utilization research. 13th edn. WHO Collaborating Centre for Drug Statistics Methodology.

5. Guidelines for Herbal ATC classification (2004) The Uppsala Monitoring Centre. WHO Collaborating Centre for International Drug Monitoring.

6. Sharma $A B$ (2008) Indian herbal market to grow by $20 \%$. The Financial Express, Economy.

7. Vaidya ABD (2006) Reverse pharmacological correlates of Ayurvedic drug actions. Indian Journal of Pharmacology 38: 311-315.

8. Chattopadhyay D, Sarkar MC, Chatterjee T, Sharma Dey R, Bag P, et al. (2009) Recent advancements for the evaluation of anti-viral activities of natural products. New Biotechnology 25: 347-368.

9. Sachs L, Tomson G (1992) Medicines and culture a double perspective on drug utilization in a developing country. Social Science and Medicine 34: 307-315.

10. WHO Policy Perspectives on Medicines (2002) Promoting rational use of medicines: core components, World Health Organization, Switzerland.

11. Chen LC, Wang BR, Chou YR, Tien JH (2005) Drug utilization pattern of Chinese herbal medicines in a general hospital in Taiwan. Pharmacoepidemiology and Drug Safety 14: 651-657.

12. Grand AL, Hogerzeil HV, Haaijer-Ruskamp FM (1999) Intervention research in rational use of drugs: a review. Health Policy and Planning 14: 89-102.
13. Sharma R, Kapoor B, Verma U (2006) Drug utilization pattern during pregnancy in North India. Indian Journal of Medical Sciences 60: 277-287.

14. Tripathi B (2000) Charak Samhita. Varanasi: Chaukhamba Subharti Prakashan. 7th edn. 8: 115-767.

15. Sharma AR, Sharma PV Sushrut Samhita. 5th edn. Varanasi: Chaukhamba Subharti Prakashan.

16. Garde GK (1996) Ashtang Hriday-Vagbhat. 8th edn. Pune: Raghuvansh Prakashan, India.

17. Shrikant Murti KR (2001) Chennai: Ved Prakashan. 3rd edn. Sharangdhar samhita, India.

18. Sharma AR (2003) Yogratnakar nighantu. 2nd edn. Varanasi: Chaukhamba Subharti Prakashan.

19. Sharma PV (1991) Dravyagun Vigyaan Benaras. Chaukhamba Publications.

20. Indian Pharmacopoeia Commission (2008) Indian Pharmacopoeia 2007. 5th edn. Ministry of Health \& Family Welfare, India.

21. Ministry of Health and Family Welfare (2004) Ayurveda Pharmacopoeia of India. 1st edn. India.

22. New Hope 360 (2006) United States Pharmacopeia and National Formulary United States Pharmacopoeia.

23. Thomson Healthcare (2007) Physician Desk Reference for Herbal Medicine 4th edn. Thomson Reuters.

24. World Health Organization (2002) Indian herbal Pharmacopoeia. Indian drug Manufacturers Association 2.

25. World Health Organization (2009) Essential Medicines and Health Products Information Portal WHO Monograph 4.

26. European Scientific Cooperative on Phytotherapy (2009) E/S/C/O/P monographs: the Scientific Foundation for Herbal Medicinal Products. 2nd edn. European Scientific Cooperative for Phytotherapy. 